\title{
Fuzziness over Randomness in Unforeseen Works of Construction Projects
}

\author{
Jarosław Konior \\ Department of Construction Technology and Management, Faculty of Civil Engineering, \\ Wroclaw University of Science and Technology, Poland
}

Copyright $\odot 2019$ by authors, all rights reserved. Authors agree that this article remains permanently open access under the terms of the Creative Commons Attribution License 4.0 International License

\begin{abstract}
A new approach to distinguish construction management models by uncertain and fuzzy states has been presented and laid out in the paper. Supplementing well recognised practical models of project and construction management, based on probabilistic and fuzzy events may make possible to transfer the weight of the change and extra orders assessment from the qualitative form to a quantitative one. This assessment, however, is naturally burdened with an immeasurable, subjective aspect. Elaboration of probability of occurrence in a construction project unforeseen building works requires application (in addition to the non - measurable, qualitative criteria) of measurable (quantitative) criteria which still appear during construction project implementation. In reimbursable engineering contracts, a random event described as an extra, supplementary building work has a random character and occurs with a specific likelihood. In lump sum contracts, on the other hand, such a random event has a fuzzy character and its occurrence is defined in a linear manner by the function of affiliation to the set of fuzzy events being identical with unforeseen events. The strive for quantitative presentation of criteria regarded by nature as qualitative and the intention to determine relations between them led to the application of the fuzzy sets theory to this issue. Their properties enable description of the unforeseen works of construction projects in an unambiguous, quantitative way. In 19 considered construction projects the lump sum from of engineering contracts are in majority, therefore, it is so crucial to apply fuzzy sets models with their fuzzy tools which makes possible to quantify of
\end{abstract}

construction projects unforeseen works as indicated in research presented in the paper. The random event for fixed fee contracts as an unforeseen building work has a fuzzy character and its occurrence is defined by a linear function of affiliation in the set of fuzzy events identical with the unforeseen events. Such fuzzy relations between faults of construction projects with impacted unforeseen works have been precisely determined in the presented research findings.

Keywords Construction Projects, Unforeseen Works, Randomness, Fuzziness

\section{Introduction}

While carrying out of construction works project managers and engineers face problems of working on the qualitative (immeasurable data) basis rather than on a quantitative one. This is why in the research of construction unforeseen works we are moving closer to fuzzy states rather than probabilistic ones.

The decision making theory presents a classical division of such situations that have been presented from three following points of view by originators of fuzzy sets theory [3], [12], [13], [14], [15]:

- Degree of uncertainties;

- Number of experts;

- $\quad$ Number of decision making phases.

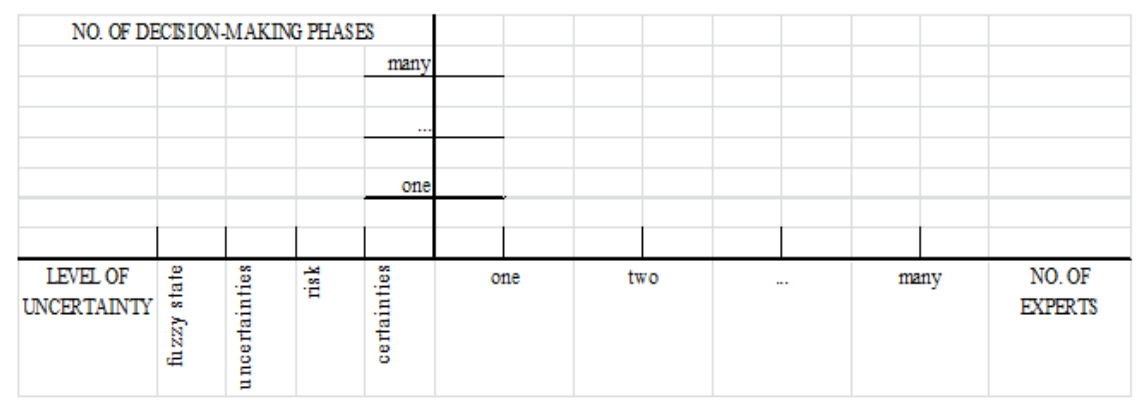

Figure 1. Classification scheme of decision making tasks in conditions of uncertainty 
In the axis 'level of uncertainty' in Figure 1, the following decisions pertaining to uncertain and fuzzy situations have been marked:

- certainties means determined events, so the entire information describing the decision making process has deterministic character, which means that possibilities of decision choice are precisely known. Decision making in such a case is limited to maximizing of the usefulness function in the value analysis.

- $\quad$ risk state stands for the entire information describing the decision making process is probabilistic, i.e. probability distributions are easily applied. Decision making process stands for optimization of the expected value of usefulness function.

- uncertainties means that even the probability distributions are unknown. Decision making relies on application of min-max strategy to ensure the best possible value of usefulness in the worst expected conditions.

- fuzzy state goes further into uncertainties which tackle not only the existence of an event appearance but its overall meaning that cannot be described by probabilistic methods.

Some other combinations are possible, e.g. by adding risk to uncertainties.

In the axis 'number of experts' the following situations have been shown: one decision maker, two, and many. If there are more than one decision maker than they may be representative of more groups or organisations that cannot be treated as a uniform group because their interests may stay in conflict with one another by representing different points of view. In the axis 'number of decision making phases' there are two fundamental situations: one phase and many phases. They reflect the problem in both aspects - static and dynamic.

By combining these groups of situations shown in three axes in Fig. 1 all possible states of making decision have been elaborated, e.g.: 'certainties - one decision expert one phase of decision making process', 'risk - two experts - many decision phases', 'uncertainties - two experts - one decision phase', etc. These combinations cover all areas of decision making theories, e.g.: two-player games, $\mathrm{N}$-player games, multiphase decision making process, etc. Unfortunately, not all of these states of making decisions are fully described by mathematical models and confirmed by practical applications. It is generally said that the further the experts go along the axis the less recognized the states of making decision process are.

To sum up, a new approach to split construction management projects into probabilistic and fuzzy view has been presented and laid out in the paper with a project management situation quite commonly met though difficult in construction lump - sum contracts: 'fuzziness many experts - many phase of decision making process' [3]. Demand for quantitative description of criteria gifted by nature as qualitative and the intention to determine relations between them led to the application of the fuzzy sets theory to problem. Their properties enable to describe the unforeseen works of construction projects in an unambiguous, quantitative way which has been applied in the research works with methods and findings presented below.

\section{Reasons for Occurrence of Unforeseen Construction Works}

Regardless of the character of predictability of the phenomenon in question the reasons for the occurrence of the supplementary and variation (unforeseen) works were referred to as faults. The faults - whether deliberate or not - may be included in the following groups depending on the cause of their occurrence and the liability of the investment process participants [1], [4]:

\subsection{Investor's Faults}

There are the following Investor's faults found out:

- $\mathrm{Z}_{11}$ - a poorly constructed business plan and an underestimated project budget,

- $\mathrm{Z}_{12}$ - inadequate investigation of the geotechnical conditions in the soil subbase,

- $\mathrm{Z}_{13}$ - a change in the assumptions pertaining to the technology and the function of the project,

- $\mathrm{Z}_{14}-$ an increase in the service loads and a change in their distribution within the building,

- $\mathrm{Z}_{15}$ - a change in the expectations and assumptions of the tenants / clients of the investor,

- $\mathrm{Z}_{16}$ - growing commercial requirements of the investor in relation to the performance capacity of the executing party,

- $\mathrm{Z}_{1 \mathrm{i}}$ - other.

\subsection{Designer's Faults}

There are the following Designer's faults pinpointed:

- $\mathrm{Z}_{21}$ - wrong assessment of the soil sub-base load bearing capacity and adoption of an inadequate foundation type,

- $\mathrm{Z}_{22}$ - incomplete identification of the buried utilities,

- $\mathrm{Z}_{23}$ - incorrect modelling of the building superstructure, improper static and strength analysis and dimensioning of the structure,

- $\quad \mathrm{Z}_{24}$ - incomplete quantity survey performance and inadequate cost estimate preparation,

- $\mathrm{Z}_{25}$ - an increase in the expenditures for Workmanship, Materials and Equipment in the working documentation and the workshop documentation when compared with the bid and a tender design,

- $\mathrm{Z}_{26}$ - inclusion in specifications of materials and plant having no product acceptance certificates for the application and sale on the Poland's construction market, 
- $\quad \mathrm{Z}_{27}$ - lacking ambiguity and cohesion between the disciplines in the design documentation,

- $\quad \mathrm{Z}_{2 \mathrm{i}}$ - other.

\subsection{Contractor's Faults}

There are the following Contractor's faults determined:

- $\mathrm{Z}_{31}$ - imperfect control of the completeness and correctness of the tender documentation preparation (as a bidder),

- $\mathrm{Z}_{32}$ - deliberate understatement of the bid value in order to increase chances for getting the contract (as a bidder),

- $\mathrm{Z}_{33}$ - preparation of an incorrect OH\&S plan,

- $\mathrm{Z}_{34}$ - application of an irrational method of the building works execution,

- $\mathrm{Z}_{35}$ - application of improper methods of the building works organization,

- $\mathrm{Z}_{36}$ - no compliance with technological regimes, quality requirements and technical conditions of the building works execution,

- $\quad \mathrm{Z}_{37}$ - defective logistics of delivery of building materials to the site,

- $\quad \mathrm{Z}_{3 \mathrm{i}}$ - other

\subsection{Faults of Building Administration Authorities and Utility Companies}

There are the following administrative faults highlighted:

- $\mathrm{Z}_{41}$ - changes in the building regulations pertaining to the project implementation,

- $\mathrm{Z}_{42}$ - not keeping of the time schedule for the execution of own tasks enabling the assumed operation of the building being constructed (e.g. the lack of the access road, the gas pressure regulating station, culverts for power supply cables, etc.),

- $\mathrm{Z}_{43}$ - freedom of interpretation as to the building inspection by the State Fire Authority, the State Work Inspection, the State Sanitary Inspection, the Environmental Protection Inspection and the Technical Inspection Office,

- $\mathrm{Z}_{44}$ - increased requirements and the scope of the obligatory inspection carried out by the building control inspection of a building for which the application for the occupancy permit was submitted,

- $\mathrm{Z}_{45}$ - possibility of objection submission by third parties in relation to the occupancy permit decision,

- $\quad \mathrm{Z}_{4 \mathrm{i}}$ - other

\section{Unforeseen Construction Works as Fuzzy Events}

\subsection{Fuzzy Sets and Fuzzy Events}

The main notion from the theory used in the paper is the fuzzy set notion [3], [12], [13], [14], [15]:. The fuzzy set may be defined in this most straightforward manner: A fuzzy set is such a set A whose elements $\mathrm{x}$ are characterized by the lack of a sharp limit between the affiliation and non-affiliation of $x$ to the set $A$. The degree of affiliation of an element $\mathrm{x}$ to the fuzzy set $\mathrm{A}$ is described by a function $\mu_{\mathrm{A}}(\mathrm{x})$ known as the affiliation function. Function $\mu_{\mathrm{A}}(\mathrm{x})$ accepts values from the interval $[0,1]$, while:

$\mu_{\mathrm{A}}(\mathrm{x})=0$ denotes the absence of any affiliation of $\mathrm{x}$ to $\mathrm{A}$, $\mu_{\mathrm{A}}(\mathrm{x})=1$ denotes full affiliation of $\mathrm{x}$ to $\mathrm{A}$.

The fuzzy set A in a certain space (in this paper it is a range of events that result in the occurrence of the supplementary and the variation building works) $X=\{x\}$, expressed as $\mathrm{A} \subseteq \mathrm{X}$, is referred to as a set of pairs:

$$
\mathrm{A}=\left\{\left(\mu_{\mathrm{A}}(\mathrm{x}), \mathrm{x}\right)\right\}, \forall \mathrm{x} \in \mathrm{X} .
$$

Thus, two main fuzzy sets can be distinguished in the discussion that follows:

- $\quad$ a fuzzy set of events (faults) that cause unforeseen building works $\mathrm{A} \subseteq \mathrm{Z}$ :

$$
\mathrm{Z}=\left\{\left(\mu_{\mathrm{Z}}(\mathrm{z}), \mathrm{z}\right)\right\}, \forall \mathrm{z} \in \mathrm{Z} \text {; }
$$

- a fuzzy set of the supplementary and the variation building works $\mathrm{B} \subseteq \mathrm{U}$ :

$$
\mathrm{U}=\left\{\left(\mu_{\mathrm{U}}(\mathrm{u}), \mathrm{u}\right)\right\}, \forall \mathrm{u} \in \mathrm{U} .
$$

In the paper, the approach proposed by Zadeh [14], [15] was used, who defined probabilities of occurrence of fuzzy events in the form of real numbers from the interval $[0,1]$. Thus, the probability of a fuzzy event, which generates a fault leading to the occurrence of the unforeseen building works during the project implementation, was defined as follows:

$P(Z)=\sum_{i=1}^{n} p\left(z_{i}\right) \mu_{z_{i}}\left(z_{i}\right)$, when $Z=\left\{z_{i}\right\}=\left\{z_{1}, z_{2}, \ldots, z_{n}\right\}$

For the fault assumed as an event equivalent, the need for the execution of the variation and the supplementary works as a fuzzy event is a probability that can be expressed with an identical relation:

$$
P(U)=\sum_{j=1}^{m} p\left(u_{j}\right) \mu_{u j}\left(u_{j}\right) \text {, when } U=\left\{u_{j}\right\}=\left\{u_{1}, u_{2}, \ldots, u_{m}\right\}
$$

\subsection{Fuzzy Relations and Their Basic Properties}

Conventional (non-fuzzy) sets enabled adequate expression of certain precisely defined properties of theoretical and observed conditions. The relation (non-fuzzy) enabled adequate expression of precisely defined interdependence between variables of these conditions (if such dependences existed) [10].

The problem appeared when it was necessary to express interdependences that were defined not very precisely, e.g.: What is the impact (cause) of faults on the need to execute 
variation and supplementary building works? The notion of a fuzzy relation was used to define the problem and record parameters of the phenomenon. Each pair of arguments $(\mathrm{x}, \mathrm{y}) \Leftrightarrow(\mathrm{z}, \mathrm{u})$ was assigned with a degree (measure) of affiliation that expresses intensity of occurrence of relations between $\mathrm{Z}$ and $\mathrm{U}$, that is how $\mathrm{Z}$ depends on $\mathrm{U}$, i.e. what interdependences (correlations) occur between them. It was assumed that $\mathrm{Z}$ and $\mathrm{U}$ as unsharp sets, determined under conditions of fuzziness, may be in a certain relation with one another. As a result, the fuzzy relation was defined as follows [2]:

A two-argument fuzzy relation $\mathrm{R}$ between two sets $\mathrm{Z}=\{\mathrm{z}\}$ and $\mathrm{U}=\{\mathrm{u}\}$ is a relation defined as a fuzzy set determined on the Cartesian product $\mathrm{Z} \times \mathrm{U}$ :

$$
\mathrm{R} \subseteq \mathrm{Z} \times \mathrm{U}=\{(\mathrm{z}, \mathrm{u}): \mathrm{z} \in \mathrm{Z}, \mathrm{u} \in \mathrm{U}\}
$$

it is thus a set of pairs:

$$
\mathrm{R}=\left\{\left(\mu_{\mathrm{R}}(\mathrm{z}, \mathrm{u}),(\mathrm{z}, \mathrm{u})\right)\right\}, \forall \mathrm{z} \in \mathrm{Z}, \forall \mathrm{u} \in \mathrm{U}
$$

where $\mu_{R}: Z \times U \rightarrow[0,1]$ is an affiliation function of the fuzzy relation $\mathrm{R}$ attributing each pair $(\mathrm{z}, \mathrm{u}): \mathrm{z} \in \mathrm{Z} \mathrm{u} \in \mathrm{U}$, with its affiliation degree $\mu_{R}(z, u) \in[0,1]$, being a measure of intensity of the fuzzy relation $\mathrm{R}$ between $\mathrm{Z}$ and $\mathrm{U}$.

The fuzzy relation may therefore be presented as follows:

$$
\mathrm{R}=\sum_{\mathrm{z}, \mathrm{u}} \mu \mathrm{R}(\mathrm{z}, \mathrm{u}) /(\mathrm{z}, \mathrm{u})
$$

The main fuzzy relation, defined at a general level in this paper, is the relation pertaining to generating faults $\mathrm{Z}$ and the occurrence of unforeseen works $U$ during the construction execution. A measure of relation between $\mathrm{Z}$ and $U$ are values equivalent to the affiliation degree $\mu_{R} \Leftrightarrow \mu_{Z, u}$. The fuzzy relation $R=Z \times U$ defined in this manner was presented as a fuzzy relation matrix.

The matrix components, representing fuzzy relations between $\mathrm{Z}$ and $\mathrm{U}$ inform us about the degree to which the fuzzy event of making design, contractor's and other faults (expressed by the intensity of occurrence of these faults) has an impact on the scale (degree) of the supplementary and variation works in relation to the basic (foreseen) works.

For all fuzzy relations $\mathrm{R} \subseteq \mathrm{Z} \times \mathrm{U}$ the following parameters were determined in fuzzy relation matrix $\mathrm{R}=\mathrm{Z} \times \mathrm{U}$ :

- domain of a fuzzy function $\mathrm{R} \subseteq \mathrm{Z} \times \mathrm{U}$, referred to as the first projection of the fuzzy function and marked as 'dom R':

$$
\mu_{\text {domR }}(\mathrm{z})={ }_{\mathrm{z} \in \mathrm{Z}} \mu_{\mathrm{R}}(\mathrm{z}, \mathrm{u}) \Leftrightarrow \underset{\mathrm{i}=1}{\mathrm{n}} \mathrm{Z}_{\mathrm{i}}=\max \left\{\mathrm{z}_{1}, \mathrm{z}_{2}, \ldots, \mathrm{z}_{\mathrm{n}}\right\}
$$

- range of fuzzy relation $\mathrm{R} \subseteq \mathrm{Z} \times \mathrm{U}$, referred to as the second projection of the fuzzy relation and marked as 'ran R'.
$\mu_{\mathrm{ranR}}(\mathrm{u})=\mathrm{V}_{\mathrm{u} \in \mathrm{U}} \mu_{\mathrm{R}}(\mathrm{z}, \mathrm{u}) \Leftrightarrow \mathrm{V}_{\mathrm{j}=1}^{\mathrm{m}} \mathrm{u}_{\mathrm{j}}=\max \left\{\mathrm{u}_{1}, \mathrm{u}_{2}, \ldots, \mathrm{u}_{\mathrm{m}}\right\}$

- height of fuzzy relation $\mathrm{R} \subseteq \mathrm{Z} \times \mathrm{U}$, referred to as the global projection of the fuzzy relation and marked as $\mathrm{h}(\mathrm{R})$

$$
\mathrm{h}(\mathrm{R})=\mathrm{V}_{\mathrm{z} \in \mathrm{Z}} \mu_{\mathrm{domR}}(\mathrm{z})=\mathrm{V}_{\mathrm{u} \in \mathrm{U}} \mu_{\mathrm{ranR}}(\mathrm{u})=\mathrm{z}_{\mathrm{z} \in \mathrm{Z}} \mathrm{u}_{\mathrm{u} \in \mathrm{U}} \mu_{\mathrm{R}}(\mathrm{z}, \mathrm{u}) \text { (8) }
$$

and, when $\mathrm{h}(\mathrm{R})=1$ then the fuzzy relation is normal and, if $h(R)<1$ it is subnormal.

\section{Cause - Effect Fuzzy Research Model}

Thus, a decision was made to make an attempt on a practical solution (while still treating sets $\mathrm{U}$ and $\mathrm{Z}$ as fuzzy ones), that involved application of the so called fuzzy relation equations that are particularly useful in diagnostics of conditional phenomena, i.e. cause - effect relations [9], [11].

A preliminary assumption was made that in the process of the practical assessment of the occurrence of the variation and the supplementary building works, the making of a fault represents the cause $(\mathrm{Z})$ and the need for bearing additional, unforeseen project works represents the effect (U) in the analysis and the control of costs that progress in an increasing manner in the construction project.

There were 19 similar projects - industrial green field plants, approximately 10.000 square meters area each, with around $10 \mathrm{mln} €$ budget - selected, investigated and researched to describe relation between project 25 faults impacts and affiliation of 10 typical unforeseen construction works of investigated lump-sum projects [5].

Typical unforeseen (extra, additional) project activities in construction have been defined as fuzzy events as follows:

- $\mathrm{U}_{1}$ - change of functional program

- $\mathrm{U}_{2}$ - application for new permits

- $\mathrm{U}_{3}$ - updated arrangements with local authorities

- $\mathrm{U}_{4}$ - amended design works

- $\mathrm{U}_{5}-$ extra ground and compound works

- $\mathrm{U}_{6}$ - extra works of building structure

- $\mathrm{U}_{7}$ - extra installation works

- $\mathrm{U}_{8}$ - extra finishing works

- $\mathrm{U}_{9}-$ extra works of building surroundings

- $\mathrm{U}_{10}$ - delays and difficulties with commissioning and maintenance

All fuzzy relations $\mathrm{R} \subseteq \mathrm{Z} \times \mathrm{U}$ corresponding to 25 indicated faults $Z_{\mathrm{ij}}$ in 4 groups and 10 typical unforeseen construction activities $U_{j}$ have been determined in fuzzy relation matrix $\mathrm{R}=\mathrm{Z} \times \mathrm{U}$ presented in the table 1 . 
Table 1. Matrix of fuzzy relation $\mathrm{R}=\mathrm{Z}$ x U for 10 typical projects unforeseen works and 25 of their selected faults

\begin{tabular}{|c|c|c|c|c|c|c|c|c|c|c|c|c|c|c|c|c|c|c|c|c|c|c|c|c|c|}
\hline & $\mathrm{Z}_{11}$ & $\mathrm{Z}_{12}$ & $\mathrm{Z}_{13}$ & $Z_{14}$ & $Z_{15}$ & $\mathrm{Z}_{16}$ & $\mathrm{Z}_{21}$ & $\mathbf{Z}_{22}$ & $\mathbf{Z}_{23}$ & $\mathbf{Z}_{24}$ & $\mathbf{Z}_{25}$ & $\mathrm{Z}_{26}$ & $\mathbf{Z}_{27}$ & $Z_{31}$ & $Z_{32}$ & $Z_{33}$ & $\mathbf{Z}_{34}$ & $Z_{35}$ & $Z_{36}$ & $\mathbf{Z}_{37}$ & $\mathrm{Z}_{41}$ & $Z_{42}$ & $\mathrm{Z}_{43}$ & $Z_{44}$ & $Z_{45}$ \\
\hline $\mathrm{U}_{1}$ & 1.00 & 0.00 & 1.00 & $\mid$\begin{tabular}{l|l} 
\\
$\mid$
\end{tabular} & $\mid 1.00$ & 1.00 & 0.00 & 0.00 & $\mid$\begin{tabular}{|l|l|}
$\mid$ \\
\end{tabular} & 0.00 & 0.00 & 0.00 & 0.05 & $\mid$\begin{tabular}{|l|l|} 
\\
\end{tabular} & 0.00 & 0.00 & 0.00 & 0.00 & 0.00 & 0.00 & 0.97 & 0,00 & 0.35 & 0,00 & 0,00 \\
\hline $\mathbf{U}_{2}$ & 0.65 & 0.37 & 0.62 & $\mid$\begin{tabular}{l|l}
$\mid$ \\
$\mid$
\end{tabular} & 0.82 & $\mid 0.89$ & 0.51 & 0.35 & $\mid 0.65$ & 0.00 & 0.00 & | 0.11 & 0.68 & 0.00 & 0.00 & 0.00 & 0.28 & 0.00 & \begin{tabular}{|l|l|} 
& 0.00 \\
\end{tabular} & 0.00 & 1.00 & 1.00 & 0.95 & 0.95 & 1.00 \\
\hline $\mathbf{U}_{3}$ & 0.53 & 0.51 & 0.35 & $\mid$\begin{tabular}{|l|l} 
& 0.68
\end{tabular} & 0.65 & 0.78 & 0.53 & 0.89 & \begin{tabular}{|l|l|} 
& 0.51
\end{tabular} & 0.00 & 0.00 & 0.00 & 0.52 & $\mid$\begin{tabular}{|l|l|} 
\\
\end{tabular} & 0.00 & 0.00 & 0.35 & 0.00 & 0.00 & 0.00 & 1.00 & 1.00 & 0.92 & 0.92 & 0.50 \\
\hline $\mathrm{U}_{4}$ & 0.85 & \begin{tabular}{|l|l|} 
& 0.58
\end{tabular} & \begin{tabular}{|l|} 
\\
\end{tabular} & 1.00 & \begin{tabular}{|l|} 
\\
\end{tabular} & 0.92 & | 0.52 & 0.92 & \begin{tabular}{|l|l|} 
& 0.98
\end{tabular} & $\mid 0.85$ & 0.91 & 1.00 & 1.00 & \begin{tabular}{|l|} 
\\
\end{tabular} & 0.17 & 0,00 & $|1.00|$ & 0.33 & 0.45 & 0.00 & 1.00 & 1.00 & 0.96 & 0.95 & 0.92 \\
\hline $\mathbf{U}_{5}$ & 0.88 & 1.00 & 0.12 & 1.00 & $\mid 0.00$ & $\mid 0.50$ & 1.00 & 1.00 & 0.22 & \begin{tabular}{|l|} 
\\
\end{tabular} & 0.32 & 0.00 & 0.12 & $\mid$\begin{tabular}{|l|}
$\mid$ \\
$\mid$
\end{tabular} & 0.90 & $|0.65|$ & 0.68 & 0.25 & 0.25 & 0.33 & 0.00 & \begin{tabular}{|l|l|} 
\\
\end{tabular} & 0.00 & $\mid$\begin{tabular}{|l|l|}
$\mid$ \\
\end{tabular} & 0.00 \\
\hline $\mathbf{U}_{6}$ & 0.91 & 0.92 & $\mid 0.88$ & 1.00 & 0.12 & 0.65 & 0.95 & 0.12 & 1.00 & 0.39 & \begin{tabular}{|l|l|} 
& 0.37 \\
\end{tabular} & 0.36 & 0.68 & $\mid 0.93$ & 0.85 & 0.66 & 0.78 & $\mid$\begin{tabular}{|l|l}
$\mid$ \\
$\mid$
\end{tabular} & \begin{tabular}{|l|l|} 
& 0.38 \\
\end{tabular} & 0.65 & 0.00 & $\mid 0.00$ & 0.65 & 0.00 & 0.00 \\
\hline $\mathbf{U}_{7}$ & 0.90 & 0.00 & 0.72 & $\mid$\begin{tabular}{l|l}
$\mid$ \\
$\mid$
\end{tabular} & 0.69 & 0.35 & 0.00 & 0.00 & 0.00 & 0.34 & \begin{tabular}{|l|} 
\\
\end{tabular} & 0.65 & 0.52 & \begin{tabular}{|l|} 
\\
\end{tabular} & 0.96 & 0.25 & 0.35 & 0.22 & 0.52 & 0.23 & 0.00 & 0.00 & 0.12 & 0.32 & 0.00 \\
\hline $\mathbf{U}_{8}$ & 0.95 & 0.00 & \begin{tabular}{|l|l|} 
& 0.38
\end{tabular} & 0.58 & 1.00 & $\mid 0.92$ & 0.00 & 0.00 & 0.00 & 0.51 & \begin{tabular}{|l|} 
\\
\end{tabular} & 0.88 & 0.85 & \begin{tabular}{|l|} 
\\
\end{tabular} & 0.97 & $|0.35|$ & 0.51 & 0.12 & 0.58 & 0.25 & 0.00 & 0.00 & 0.14 & 0.23 & 0.00 \\
\hline $\mathbf{U}_{9}$ & 0.89 & 0.22 & 0.11 & 0.26 & 0.25 & \begin{tabular}{|l|l|} 
& 0.26
\end{tabular} & 0.21 & 0.89 & 0.00 & \begin{tabular}{|l|} 
\\
\end{tabular} & 0.21 & 0.05 & 0.03 & \begin{tabular}{|l|}
$\mid$ \\
$\mid$
\end{tabular} & 0.85 & $|0.12|$ & \begin{tabular}{|l|l|} 
& 0.12
\end{tabular} & 0.05 & 0.15 & $\mid$\begin{tabular}{|l|l} 
\\
\end{tabular} & 0.00 & \begin{tabular}{|l|l|} 
& 0.00 \\
\end{tabular} & \begin{tabular}{|l|l}
0.02 \\
\end{tabular} & 0.02 & 0.00 \\
\hline $\mathrm{U}_{10}$ & 0.97 & 0.66 & 0.52 & 0.78 & 0.88 & $\mid$\begin{tabular}{|l|}
$\mid$ \\
\end{tabular} & 0.60 & 0.09 & 0.68 & 0.12 & 0.11 & 1.00 & 0.65 & 0.65 & 0.66 & 0.14 & $\mid 0.65$ & 0.09 & 0.72 & 0.16 & 0.35 & $|0.99|$ & 1.00 & 1.00 & 1.00 \\
\hline & & & & & $66 / \mathrm{Z}$ & $33+$ & $00 / 2$ & +0.33 & $\begin{array}{l}5+1.00 / \\
Z 35+0\end{array}$ & $\begin{array}{r}\text { do } \\
/ \mathrm{Z16}+1 \\
.72 / \mathrm{Z3}\end{array}$ & $\begin{array}{l}\text { domain } \\
1.00 / \mathrm{Z} 2 \\
36+065\end{array}$ & $\begin{array}{l}\text { of fuzz } \\
\text { 21+1.0 } \\
5 / \mathrm{Z} 37+1\end{array}$ & $\begin{array}{l}\text { zy relat } \\
0 / \mathbf{Z} 22+ \\
1.00 / Z\end{array}$ & $\begin{array}{l}\text { tion don } \\
+1.00 / 2 \\
41+1.0\end{array}$ & $\begin{array}{l}\mathrm{Z} 23+0.8 \\
\mathrm{~b} 0 / \mathrm{Z} 42+\end{array}$ & $+1.00 / 2$ & $/ \mathrm{Z} 43+1$ & $1.00 / \mathrm{Z} 4$ & $44+1.00$ & $\begin{array}{l}\mathrm{Z} 26+1 . \\
0 / \mathrm{Z} 45\end{array}$ & & & & & \\
\hline & & & rang & ge of fu & lzzy rel & lation $r$ & ran & $U)=1.00$ & $0 / \mathrm{U} 1+1$ & $1.00 / \mathrm{U} 2$ & $2+1.00$ & //U3+1. & $.00 / \mathrm{U} 4+$ & $+1.00 / \mathrm{t}$ & $\mathrm{U} 5+1.00$ & $00 / \mathrm{U} 6+c$ & $+0.96 / U$ & $U 7+1.00$ & $0 / \mathrm{U} 8+0$ & $0.89 / \mathrm{Ug}$ & $99+1.00$ & & & & \\
\hline & & & & & & & & & & & & & & & & & & & & & & & & & \\
\hline & & & & & & & & & & & ou & $\frac{y 1}{1}$ & 100 & $k(2$ & \}$=$ & & & & & & & & & & \\
\hline
\end{tabular}

\section{Key Findings}

There are three main conclusions from elaborating the relations $\mathrm{R} \subseteq \mathrm{Z} \times \mathrm{U}$ in fuzzy sets categories [8]:

- $\quad$ around 3/4 out of $250 \mathrm{Zij}$ and $\mathrm{Uj}$ relations pair are linked with each other in "i”" columns, half of them with $\mathrm{R}$ over 0.5 which indicates significant alliances

- $\quad$ there is only one fuzzy category of fault Z11 (a poorly constructed business plan and an underestimated project budget) which has had an overall and strong $(\mathrm{R}>0.5)$ impact on fuzzy unforeseen works U1-10 in all 10 investigated projects,

- the height $h(\mathrm{R})$ of the tested fuzzy relations $\mathrm{R} \subseteq \mathrm{Z} \times \mathrm{U}$ is getting to normal (1) not only as one maximum in the relation matrix but appears in 25 cases $\left(10 \%\right.$ of $\mathrm{Z}_{\mathrm{ij}}$ and $\mathrm{U}_{\mathrm{j}}$ relations)

The occurrence during the construction execution phase of works that were unforeseen at the project preparation stage (known in the building industry as variation or supplementary works) is a common element of the investment process [5], [6]. It was possible to calculate the range, the domain and the height of the fuzzy relations $\mathrm{R} \subseteq \mathrm{Z} \times \mathrm{U}$ as quantitative values.

These undesirable, unforeseen events have their origins already during the tender procedure and the creation of the form of the construction works contract between the Employer and the Contractor, regardless of whether the project is privately funded or represents a public procurement. The well-known and commonly used engineering contracts, such as the FIDIC, the VOB, the NEC or the JCT provide a choice of various systems for the funding and accounting of the building works covered by the contract. With regard to the possibility of occurrence of the unforeseen works, the varied forms of contracts may be divided in two groups:

- $\quad$ contracts based on reimbursable costs (target fee), which by their nature provide for the occurrence of the supplementary and the variation works that are subject of the as-built accounting between the employer and the contractor. Here, the random event described as an unforeseen building work has a random character and occurs with a specific, determinable probability.

- $\quad$ lump sum (fixed fee) contracts according to which the need for the performance of the variation and the supplementary works may arise only during the project execution phase. In this case, the random event defined as an unforeseen building work has a fuzzy character and its occurrence is defined by a linear function of affiliation in the set of fuzzy events identical with the unforeseen events.

In Poland and Central Europe (also in case of 19 researched construction projects) the group b) of lump sum engineering contracts takes an overwhelming majority over the group a), especially in the area of non-public procurement. Therefore, it is so crucial to apply fuzzy sets models with their fuzzy tools which makes possible to convert qualitative inputs of construction projects into quantitative outputs priceless for construction enterprises cycle of their quality improvements [5], [6].

\section{Discussion}

A new approach to distinguish construction management models by uncertain and fuzzy states has been presented 
and laid out in the paper. Demand for quantitative description of criteria gifted by nature as qualitative and the intention to determine relations between them led to the application of the fuzzy sets theory to problem. Their properties enable to describe the unforeseen works of construction projects in an unambiguous, quantitative way which has been applied in the research works with methods and findings presented in the paper.

The research works, the methods and the overall approach has been inspired already in nineties by Kosko [6] who firstly differ fuzziness from probability. After that Al-Humaidi and Hadipriono [9] applied fuzzy logic approach to delays in construction projects but the author of the paper extended and developed their methodology for quantifying fuzzy impacts of faulty events on unforeseen construction works. Also, the basis of the research steamed from fuzzy logic modelling for construction risk management described by Nasirzadeh, Afshar, Khanzadi and Howick [9] and the breakdown construction project risk assessment using fuzzy logic presented by Tah and Carr [11]. Actually, what differs and improves the research works presented in the paper are fuzzy tools and models are applied fuzzy relations and their proprieties. All fuzzy relations corresponding to 25 indicated faults in 4 groups and 10 typical unforeseen construction activities have been determined in fuzzy relation matrix with precisely figured out and comparative values. This is far more in comparison to presented model by Perfilieva and Gottwald [10] who elaborated approximate solvability of fuzzy relation equations only.

Certainly, the author of the paper came back to the basis of fuzzy sets bibliography laid out by Zadeh [14], [15] and Yager [12], [13]. However, a slightly simplified approach that attributed a fuzzy number to the probability of fuzzy events, as opposed to the approach presented by Yager according to which the probabilities are fuzzy events. It is important that no differences between the notion of fuzziness and randomness were taken into consideration in the paper. It was only assumed that despite the fact that these two phenomena are different and described in a different way, they may (as two types of uncertainty) occur together [4], [7], [8].

The main rules of the fuzzy sets calculus shall be supplemented with the following comments: The fact that the affiliation function of the fuzzy set assumes values from the interval $[0,1]$ may prompt a hasty conclusion that fuzziness is some hidden type of randomness, and therefore the fuzzy sets theory is in fact nothing new when compared with the probability theory. Differences between the fuzziness and the randomness concern, however, both their nature and formal differences between the probabilistic calculation and the calculations in fuzzy sets. The nature of these phenomena is related to the issue of uncertainty of the randomness and the fuzziness type. Thus, in the case of the randomness, the event is precisely determined, whereas its occurrence is uncertain. The randomness may, therefore, be identified with uncertainty as regards the affiliation or non-affiliation of an element to the set (in the paper: faults in the unit price contracts). A different situation pertains to the fuzziness, as it concerns the same degree of affiliation of an element to the set (in the paper: faults in the lump sum contracts). Thus, an event is not strictly defined in this case. Such events, analysed in the paper, are the faults that result in the possibility of occurrence of unforeseen works reflected in the schedule of works for a construction project. The author is of a view that their nature combines both the fuzziness and the randomness [4], [8].

\section{Summary}

The approach presented in the paper - the methodological assumptions and the fuzzy sets method to measure unpredictable construction works - should be treated as an exploratory work. Thus, it is an attempt at the recognition of the mechanism of the reasons and effects of phenomena, which an Employer, a Contractor and a Contract Engineer meet in the management of construction enterprises. This assessment, however, is naturally burdened with an immeasurable, subjective aspect. Supplementing well recognised practical models of project and construction management, based on probabilistic and fuzzy events may make it possible to transfer the weight of the variation and the supplementary orders assessment from the qualitative form to a quantitative one. The intention of the author is to carry out further work on the project and construction procedures using the approach described above. Such approach has been laid out, explained and proved in the paper so far.

\section{REFERENCES}

[1] Al-Humaidi H. M., Hadipriono T. F., Fuzzy logic approach to model delays in construction projects using rotational fuzzy fault tree models. Civil Engineering and Environmental Systems 2010, pp. 329-351.

[2] Chan K. Y., Kwong C. K., Dillon T. S., Fung K. Y., An intelligent fuzzy regression approach for affective product design that captures nonlinearity and fuzziness. Journal of Engineering 2011, pp. 523-542

[3] Kacprzyk J., Fuzzy sets in the system analysis. PWN, Warsaw 1986.

[4] Konior J. Fuzzy relations in supplementary and variation building works. Management of the investment process in construction. $6^{\text {th }}$ All Polish Seminar BUDIN 2004, Wrocław 2004

[5] Konior J., Quality Management Systems in PM Group Poland. Project Management Group procedures, Wroclaw 2014.

[6] Kosko B., Fuzziness vs. probability. International Journal of 
General Systems 1990, pp. 211-240.

[7] Marcinkowska E., Decision making problems in the planning of buildings and construction processes. Wrocław University of Technology. Monographs. Wrocław 1986.

[8] Kapliński O., (editor) Analytical methods and models in the building project engineering. PAN, KILiW, Warsaw 2007, pp. 249-284.

[9] Nasirzadeh F, Afshar A., Khanzadi M., Howick S., Integrating system dynamics and fuzzy logic modelling for construction risk management. Construction Management and Economics 2008, pp. 1197-1212.

[10] Perfilieva I., Gottwald S., Solvability and approximate solvability of fuzzy relation equations. International Journal of General Systems 2003, pp. 361-372.

[11] Tah J. H. M., Carr V., A proposal for construction project risk assessment using fuzzy logic. Construction Management and Economics 2000, pp. 491-500.

[12] Yager R. R. A note on probabilities of fuzzy events. Information and Science; vol. 18. Iona College 1979

[13] Yager R. R. On the fuzzy cardinality of a fuzzy set. International Journal of General Systems 2007, pp. 191-206.

[14] Zadeh L. Fuzzy sets and systems. System theory. Politechnic Press. Red. J. Fox. Berkeley 1965.

[15] Zadeh L. Fuzzy sets and systems. International Journal of General Systems 1990, pp. 129-138. 